\title{
Supplemental information to: \\ Structural evolution of the chromophore in the primary stages of trans/cis isomerization in photoactive yellow protein
}

\author{
Karsten Heyne, ${ }^{\dagger} *$ Omar F. Mohammed,$^{\dagger}$ Anwar Usman, ${ }^{\dagger}$ Jens Dreyer, ${ }^{\dagger}$ \\ Erik T.J. Nibbering, ${ }^{\dagger} *$ and Michael A. Cusanovich ${ }^{\dagger, \aleph_{*}}$
}

Max Born Institut für Nichtlineare Optik und Kurzzeitspektroskopie, Max-Born-Strasse 2A,D12489 Berlin, Germany, and Department of Biochemistry and Molecular Biophysics, University of Arizona, Tucson, Arizona 85721, USA

Received: March 3, 2005; In Final Form: November 1, 2005

\section{Full listing of Reference 29}

Frisch, M. J.; Trucks, G. W.; Schlegel, H. B.; Scuseria, G. E.; Robb, M. A.; Cheeseman, J. R.; Zakrzewski, V. G.; Montgomery, J. A.; Stratmann, R. E.; Burant, J. C.; Dapprich, S.; Millam, J. M.; Daniels, A. D.; Kudin, K. N.; Strain, M. C.; Farkas, O.; Tomasi, J.; Barone, V.; Cossi, M.; Cammi, R.; Mennucci, B.; Pomelli, C.; Adamo, C.; Clifford, S.; Ochterski, J.; Petersson, G. A.; Ayala, P. Y.; Cui, Q.; Morokuma, K.; Malick, D. K.; Rabuck, A. D.; Raghavachari, K.; Foresman, J. B.; Cioslowski, J.; Ortiz, J. V.; Stefanov, B. B.; Liu, G.; Liashenko, A.; Piskorz, P.; Komaromi, I.; Gomperts, R.; Martin, R. L.; Fox, D. J.; Keith, T.; Al-Laham, M. A.; Peng, C. Y.; Nanayakkara, A.; Gonzalez, C.; Challacombe, M.; Gill, P. M. W.; G. Johnson, B.; Chen, W.; Wong, M. W.; Andres, J. L.; Head-Gordon, M.; Replogle, E. S.; Pople, J. A. Gaussian 98 (Revision A.2); Gaussian, Inc.: Pittsburgh PA., 1998.

\section{Previous work on vibrational band assignments}

Until now three different approaches have been followed in the elucidation of the nature of the vibrational bands of PYP observed in low-temperature trapped intermediates and in transient states of solution phase PYP. Chromophore model systems enable identification of marker modes of functional groups, such as phenolate ring vibrations or the $\mathrm{C}=\mathrm{O}$ stretching mode. ${ }^{1-4}$ PYP mutants where specific molecular units have been changed reveal the distinct contributions of these units to the vibrational spectra. For instance, in the E46Q PYP mutant Glu46 has been exchanged by Gln, and with this mutant it has been possible to identify the $\mathrm{C}=\mathrm{O}$ stretching mode of the $\mathrm{COOH}$-group of Glu46. ${ }^{5,6}$ Isotope substitution provides direct insight into the involvement of motions of specific atoms in the normal modes underlying the vibrational transitions. $H / D$ exchange at the $\mathrm{C}_{2}$ and $\mathrm{C}_{4}$ positions, for instance, affect vibrational modes to which the phenolate group contributes. $\mathrm{H} / \mathrm{D}$ exchange at $\mathrm{C}_{8}$ reveals the vibrations with motions of the ethylenic group, and ${ }^{12} \mathrm{C}-{ }^{13} \mathrm{C}$ exchange at $\mathrm{C}_{9}$ affects modes with $\mathrm{C}=\mathrm{O}$ stretching involvement. The latter approach of isotope subsitution has been pursued in an extensive study of lowtemperature trapped intermediates ${ }^{3,7}$ The determination of marker modes in these studies have provided conclusive evidence on structural changes that accompany the transition of the P-state to the intermediate $\mathrm{I}_{1}$ and $\mathrm{I}_{2}$ states and the low-temperature trapped intermediates $\mathrm{PYP}_{\mathrm{B}}, \mathrm{PYP}_{\mathrm{H}}, \mathrm{PYP}_{\mathrm{L}}$ and $\mathrm{PYP}_{\mathrm{M}}$.

\section{Dark P state chromophore geometry}

For the electronic ground dark state $\mathrm{P}$, where the chromophore is in the trans configuration, we focus our analysis on the spectral range from 1800 to $1660 \mathrm{~cm}^{-1}$ and 1450 to $970 \mathrm{~cm}^{-1}$ of the fingerprint region, where amide I and amide II mode contributions are negligible. We record thirteen bleached bands with a magnitude large enough to determine the dichroic ratio (Table S1). In the spectral range from 1450 to $970 \mathrm{~cm}^{-1}$ four bands strongly support the chromophore geometry with the $\mathrm{C}=\mathrm{O}$ tilted out-of-plane (3PYP structure, Fig. $4 \mathrm{~b}$ ). These four bands are the hydrogen out-of-plane (H-oop) $\mathrm{HC}_{7}=\mathrm{C}_{8} \mathrm{H}$ wagging mode at $986 \mathrm{~cm}^{-1}$, the $\mathrm{C}_{8}-\mathrm{C}_{9}$ trans stretching mode at $1060 \mathrm{~cm}^{-1}$, the $\delta \mathrm{CH}(9 \mathrm{a})$ phenolate vibration (also indicated as $\mathrm{Y} 9 \mathrm{a}$ ) at $1166 \mathrm{~cm}^{-1}$ and the $\mathrm{C}=\mathrm{C}-\mathrm{C}(-\mathrm{S}-)=\mathrm{O}$ stretching vibration at $1300 \mathrm{~cm}^{-1} \cdot{ }^{1-3,7}$

Using the $3 \mathrm{PYP} / 1 \mathrm{NWZ}$ geometry the calculated frequency $v^{\mathrm{c}}{ }_{\gamma \mathrm{HCCH}}=996 \mathrm{~cm}^{-1}$ and angle $\Theta_{\gamma \mathrm{HCCH}}^{\mathrm{c}}=25^{\circ}$ of the H-oop mode correspond much better to the experimental values of $v^{\mathrm{e}}=986 \mathrm{~cm}^{-1}$ and $\Theta^{\mathrm{e}}=31 \pm 5^{\circ}$ than the values of $v_{\gamma \mathrm{HCCH}}^{\mathrm{c}}=952 \mathrm{~cm}^{-1}$ and $\Theta_{\gamma \mathrm{HCCH}}^{\mathrm{c}}=82^{\circ}$ calculated with the $3 \mathrm{PHY}$ structure.

Furthermore, the $\mathrm{C}_{8}-\mathrm{C}_{9}$ trans stretching vibration at $v^{\mathrm{e}}{ }_{\mathrm{vC8C9}}=1060 \mathrm{~cm}^{-1}$, assigned as a trans geometry marker band $^{3}$, has an angle of $\Theta^{\mathrm{e}}{ }_{\mathrm{VC} 8 \mathrm{C} 9}=23 \pm 5^{\circ}$. This is in better agreement with the values for the $3 \mathrm{PYP} / 1 \mathrm{NWZ}$ structure $\left(v^{\mathrm{c}}{ }_{\mathrm{vC} 8 \mathrm{C} 9}=1117 \mathrm{~cm}^{-1}\right.$ and $\left.\Theta^{\mathrm{c}}{ }_{\mathrm{NC} 8 \mathrm{C} 9}=18^{\circ}\right)$ than for the planar 3PHY geometry (calculated values of $v^{\mathrm{c}}{ }_{\mathrm{CC} 6 \mathrm{C} 7}=$ $1141 \mathrm{~cm}^{-1}$ and $\Theta^{\mathrm{c}}{ }_{\mathrm{V} 66 \mathrm{C} 7}=5^{\circ}$ or $v^{\mathrm{c}}{ }_{\mathrm{vC} 8 \mathrm{C} 9}=939 \mathrm{~cm}^{-}$ ${ }^{1}$ and $\Theta^{\mathrm{c}}{ }_{\mathrm{vC} 8 \mathrm{C} 9}=18^{\circ}$ ).

The marker band for a deprotonated chromophore at $1166 \mathrm{~cm}^{-1}$ has been assigned to the $\delta \mathrm{CH}(9 \mathrm{a})$ (or Y9a) vibration. ${ }^{2}$ This band also exhibits different vibrational character for the two reported trans structures. While the calculations for the $3 \mathrm{PYP} / 1 \mathrm{NWZ}$ structure supports the assignment with a frequency of $v_{\delta \mathrm{CH}(9 \mathrm{a})}^{\mathrm{c}}=1161 \mathrm{~cm}^{-1}$, the calculations for the 3PHY structure result in a frequency of $v_{\delta \mathrm{CH}(9 \mathrm{a})}^{\mathrm{c}}=1092 \mathrm{~cm}^{-1}$ and a vibrational character with additional contributions of in-plane hydrogen $\mathrm{HC}_{7}=\mathrm{C}_{8} \mathrm{H}$ bending. In addition to that, the low-temperature study of 
Imamoto et al. reveals that $\mathrm{H} / \mathrm{D}$ exchange at the chromophore positions $\mathrm{C}_{2}$ and $\mathrm{C}_{4}$ leads to a significant frequency down shift of more than $90 \mathrm{~cm}^{-1}$ (no absorption band between 1170 and $\left.1060 \mathrm{~cm}^{-1}\right){ }^{7} \mathrm{H} / \mathrm{D}$ exchange at these positions down shifts the calculated $\delta \mathrm{CH}(9 \mathrm{a})$ frequency position for the $3 \mathrm{PYP} / 1 \mathrm{NWZ}$ geometry by $-92 \mathrm{~cm}^{-1}$ (Table S2). In contrast, for the planar 3PHY geometry H/D exchange leads to a significantly minor frequency down shift of $-64 \mathrm{~cm}^{-1}$ due to the in-plane hydrogen $\mathrm{HC}_{7}=\mathrm{C}_{8} \mathrm{H}$ bending contribution (Table S3).

Finally, around $1300 \mathrm{~cm}^{-1}$ a $\mathrm{C}-\mathrm{C}(-\mathrm{S}-)=\mathrm{O}$ stretching vibration is observed ${ }^{1}$. We measure an angle of $\Theta^{\mathrm{e}}{ }_{\mathrm{vCCSO}}$ $=29 \pm 3^{\circ}$, whereas we calculate values of $\Theta^{\mathrm{c}}{ }_{\mathrm{C} 8 \mathrm{C} 9}=9^{\circ}$ with the $3 \mathrm{PHY}$ structure. For the $3 \mathrm{PYP} / 1 \mathrm{NWZ}$ geometry three vibrations are located around $1300 \mathrm{~cm}^{-1}$ with angles of 13, 18 and 59 degrees. This implies that our experimentally determined angle may be the resulting average value of these overlapping bands.

For one single band we found an apparent better correspondence for the $3 \mathrm{PHY}$ planar geometry. This band, located at $1445 \mathrm{~cm}^{-1}$, has a measured angle $\Theta^{\mathrm{e}}=$ $42 \pm 10^{\circ}$. In the case of the $3 \mathrm{PHY}$ geometry two vibrational transitions with angles of 50 and 12 degrees contribute to the signal. In contrast, the value calculated with the $3 \mathrm{PYP} / 1 \mathrm{NWZ}$ geometry is $\Theta_{\text {phe }}^{\mathrm{c}}=24^{\circ}$. We feel that this contrasting behaviour may be caused by interference of the bleach signals with positive absorbance bands of the $\mathrm{I}_{0}$ state.

\section{Orientation of the COOD-group of Glu46 in the P, \\ $\mathbf{P} *$ and $\mathbf{I}_{0}$ states}

In the early stages of isomerization of PYP from the $P$ to the $I_{0}$ state geometric changes are primarily due to chromophore rearrangements. Only the carboxyl side group of Glu46 exhibits a marked response upon electronic excitation. Analysis of the direction of the $v \mathrm{C}=\mathrm{O}$ transition dipole moment of the COOD group of Glu46 provides insight into the response of the protein surroundings to chromophore rearrangements. The direction of the $\mathrm{C}=\mathrm{O}$ vibrational transition moment is similar in the $\mathrm{P}$ and $\mathrm{P}^{*}$ states indicating that the COOD side group of Glu46 does not change its orientation upon electronic excitation. Instead, optical excitation of PYP leads to a weakening of the hydrogen bond between Glu46 and the phenolate of the chromophore, presumably due to a net charge flow from the phenolate to the $\left(\mathrm{C}_{9}=\mathrm{O}\right)-\mathrm{S}$ region of the chromophore. Moreover, when $\mathrm{P}^{*}$ relaxes to the first product state $\mathrm{I}_{0}$, no transient response of Glu46 is observed for either polarization directions of the mid-IR probe pulse. From this we conclude that the hydrogen bond between Glu46 and the phenolate of the chromophore recovers its strength while retaining the orientation of the COOD-group. As a result we can conclude that in the primary stages of the PYP photoinduced geometry changes the chromophore isomerization reaction does not involve a significant relocation of the oxygen side of the phenolate group that is directly linked to Glu46.

Because additional calculations including Glu46 show that deviation of the $v \mathrm{C}=\mathrm{O}$ transition dipole moment to the $\mathrm{C}=\mathrm{O}$ double bond direction is less than $20^{\circ}$, we directly calculate the angle between the electronic transition dipole moment of the chromophore and the $\mathrm{C}=\mathrm{O}$ double bond direction of Glu46 to be $\Theta_{\text {Glu46 }}^{c}=61 \pm 20^{\circ}$ for the planar 3PHY geometry. For the slightly tilted chromophore geometries $3 \mathrm{PYP}$ and $1 \mathrm{NWZ}$ we calculate $\Theta_{\text {Glu46 }}^{\mathrm{c}}=35 \pm 20^{\circ}$ and $\Theta_{\text {Glu46 }}^{\mathrm{c}}=72 \pm 20^{\circ}$, respectively. The measured angle of $\Theta_{\text {Glu }}^{\mathrm{e}}=84 \pm 6^{\circ}$ has the best correspondence with the $1 \mathrm{NWZ}$ structure. From that we conclude that although the 3PYP structure, obtained with X-ray diffraction on crystalline PYP, is a better representation of the chromophore geometry of PYP in solution, we expect that the flexible amino acids in the protein binding pocket may be more sufficiently described with the 3PHY structure, that has been obtained with nuclear magnetic resonance on solution phase PYP. However, the more recent refined $1 \mathrm{NWZ}$ structure obtained with $\mathrm{X}$-ray diffraction on crystalline PYP turns out to describe most appropriately both the tilted chromophore trans geometry and the nearly perpendicular orientation of the $\mathrm{C}=\mathrm{O}$ group of Glu46. Regretfully a more refined $\mathrm{PYP}_{\mathrm{B}}$ structure has not been reported so far, and thus it remains a future task to test further the structural similarities between the transient $\mathrm{I}_{0}$ and $\mathrm{PYP}_{\mathrm{B}}$ states.

\section{First intermediate $I_{0}$ state chomophore geometry}

For the first intermediate $\mathrm{I}_{0}$ state we observe five chromophore bands in the difference spectrum, but only three are located in the spectral range not potentially affected by amide I and amide II absorptions.

The $\mathrm{C}_{8}-\mathrm{C}_{9}{ }^{\text {cis }}$ marker band for the cis chromophore geometry ${ }^{3}$, experimentally observed at $v^{\mathrm{e}}{ }_{\mathrm{VC} 8 \mathrm{C} 9}=1000$ $\mathrm{cm}^{-1}$ is calculated to absorb at $v^{\mathrm{c}}{ }_{\mathrm{C} 8 \mathrm{C} 9}=972 \mathrm{~cm}^{-1}$ in the case of the low-temperature trapped cis chromophore 3PYP geometry (Fig. 4e). A better correspondence with experiment results in the case of the chromophore with relaxed planar geometry with $v^{\mathrm{c}}{ }_{\mathrm{VC} 8 \mathrm{C} 9}=983 \mathrm{~cm}^{-1}$ (Fig. 4d).

The vibrational band at $1495 \mathrm{~cm}^{-1}$, with measured angle $\Theta^{\mathrm{e}}=35 \pm 4^{\circ}$ (Table S1), is probably caused by several modes. For the 3PYP cis geometry we calculate two corresponding vibrations around this frequency position with angles of 18 and 4 degrees (Table S4). Here, also the relaxed cis chromophore geometry has a better correspondence with the experimental signals as three vibrations with calculated angles of 30,10 and 26 degrees can contribute (Table S4).

Strikingly better results are obtained in the calculations for the vibrational band experimentally observed at $v^{\mathrm{e}} \mathrm{CO}=1669 \mathrm{~cm}^{-1}$ with an angle of $\Theta_{\mathrm{CO}}^{\mathrm{e}}=69$ $\pm 10^{\circ}$. This vibration has been assigned to the $\mathrm{C}=\mathrm{O}$ stretching vibration in $\mathrm{I}_{1}$ by Unno et al. ${ }^{4}$ With the relaxed planar chromophore geometry we calculate a vibration with dominant $\mathrm{C}=\mathrm{O}$ stretching character located at $v_{\mathrm{CO}}^{\mathrm{c}}=1696 \mathrm{~cm}^{-1}$ with an angle $\Theta_{\mathrm{CO}}^{\mathrm{c}}=76^{\circ}$, in good agreement with the experimental values. In contrast, for the 3PYP cis chromophore geometry two bands with frequencies of 1639 and $1787 \mathrm{~cm}^{-1}$ and angles of 5 and $16^{\circ}$ have a vibrational mode character with little $\mathrm{C}=\mathrm{O}$ stretching involvement (Table S4). From this latter feature we conclude that only the relaxed planar cis chromophore geometry, as presented in Fig. $4 \mathrm{~d}$, is responsible for the measured vibrational frequencies and angles in the $\mathrm{I}_{0}$ state. 


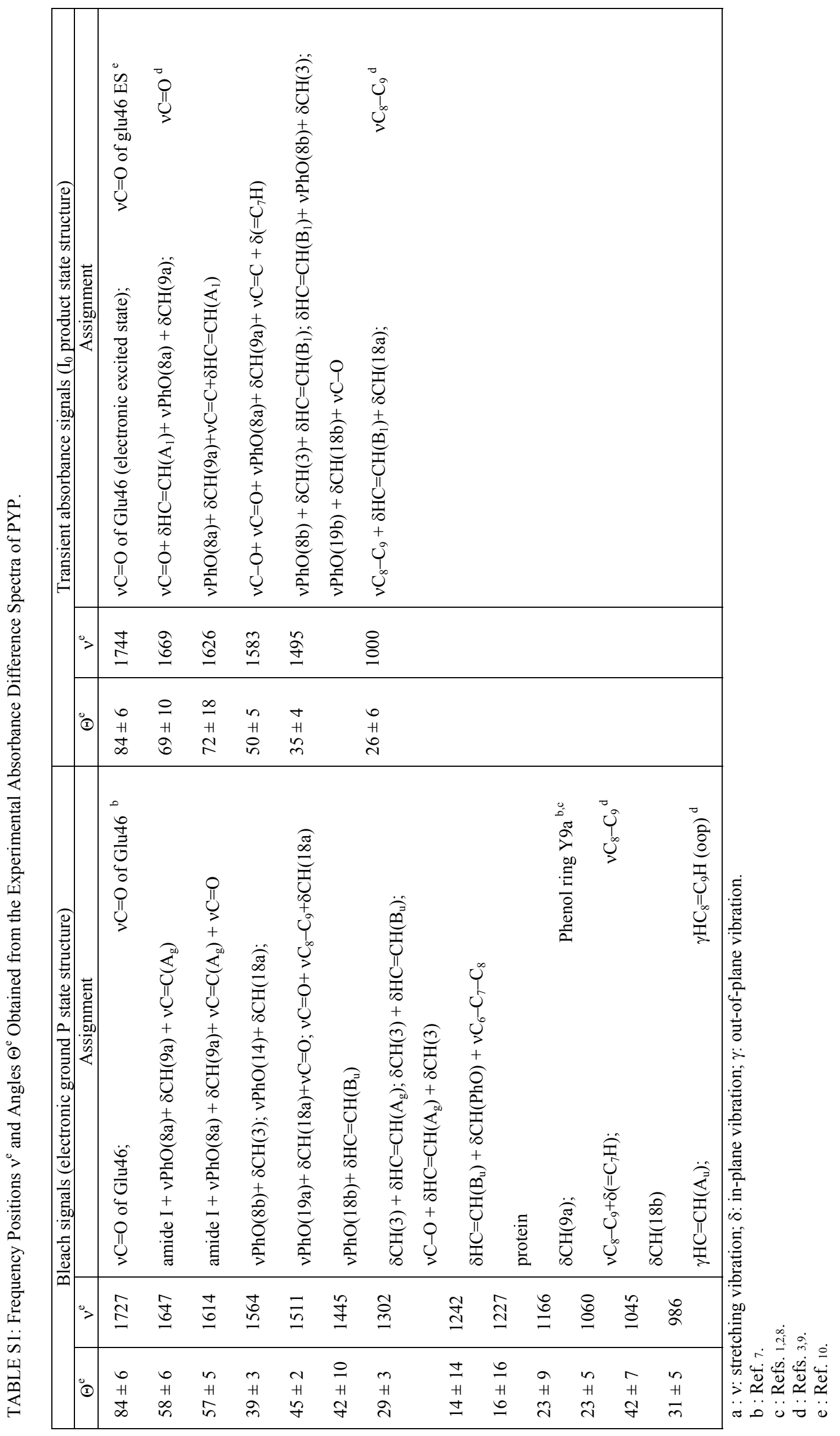




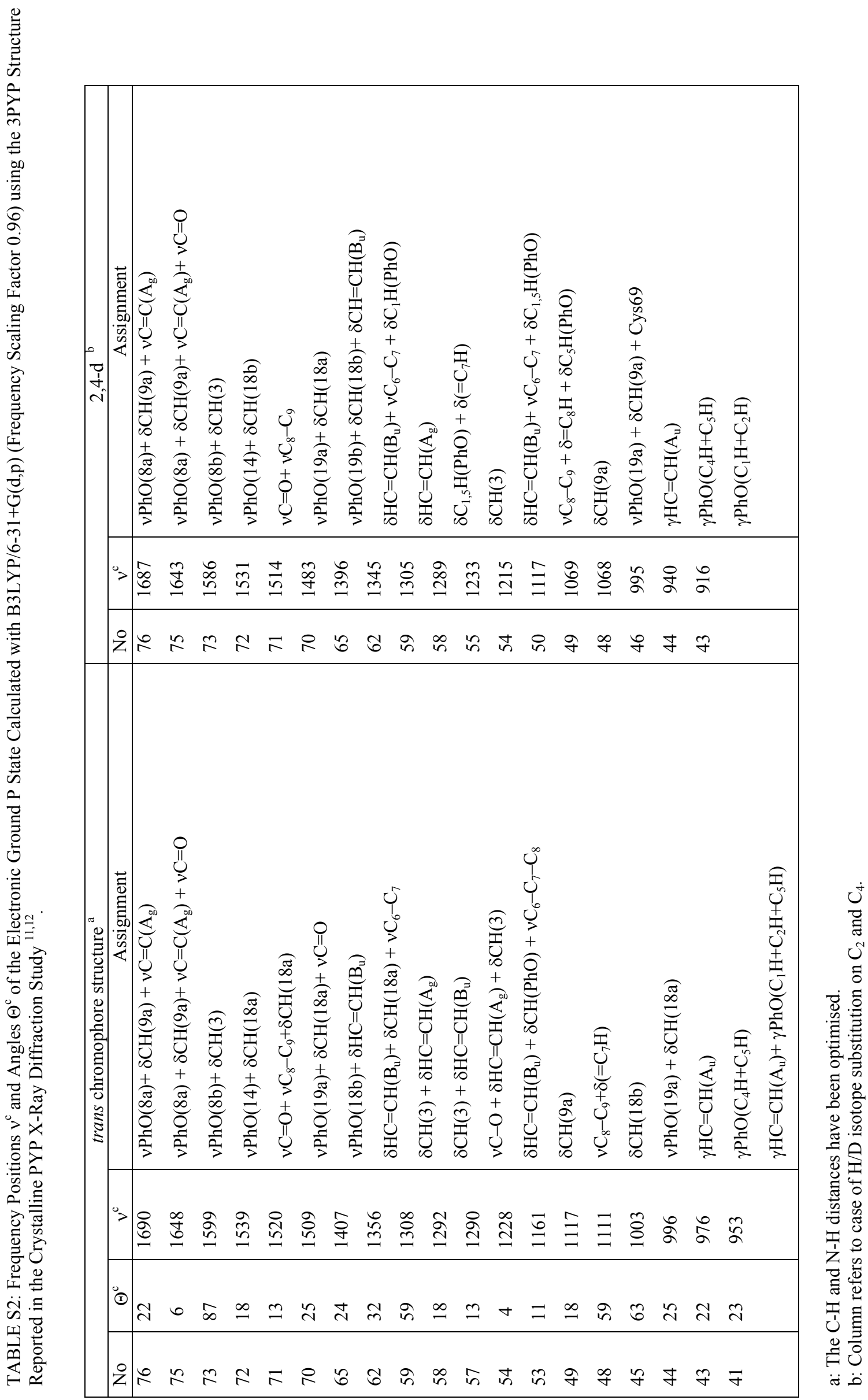




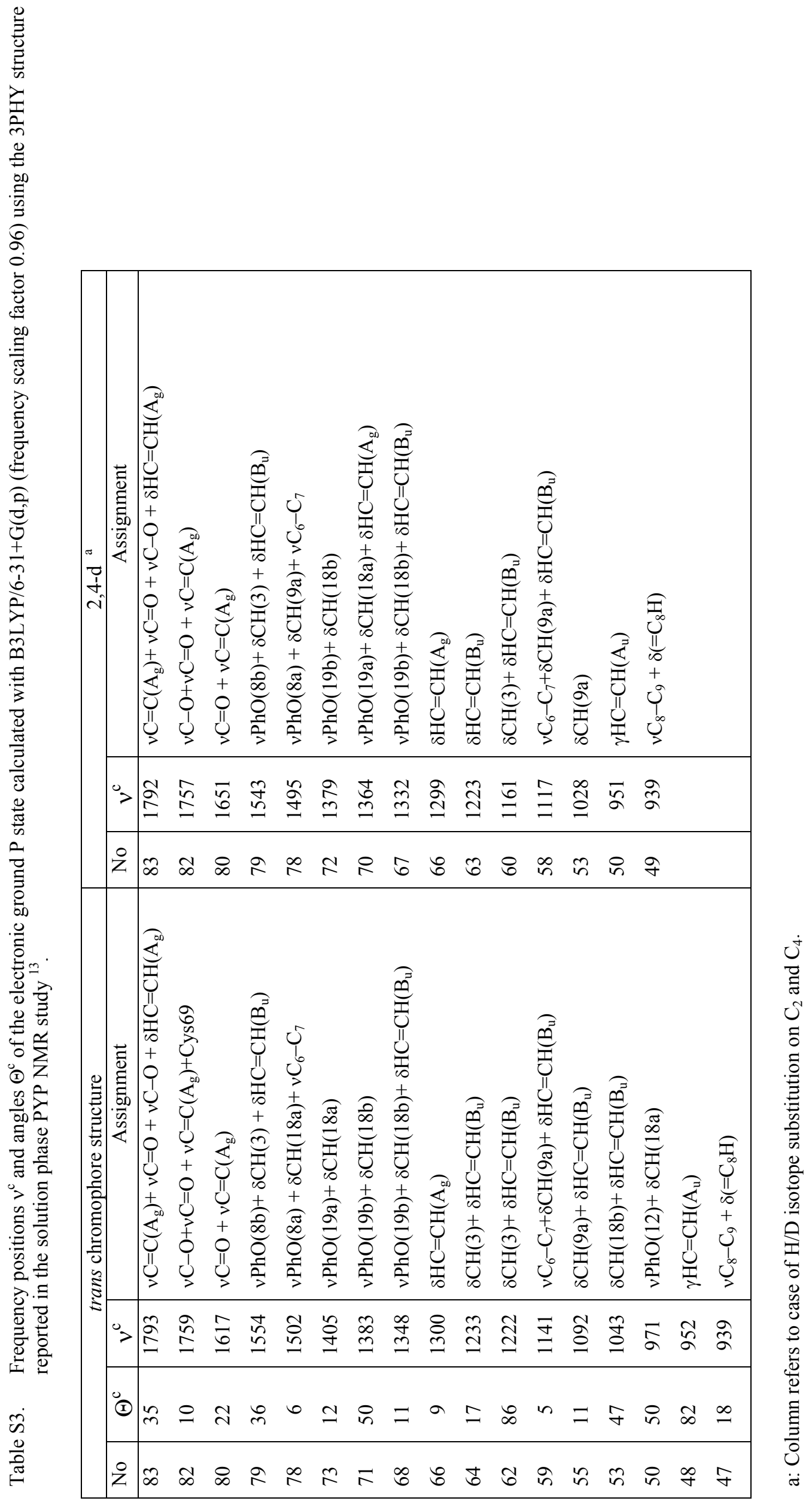




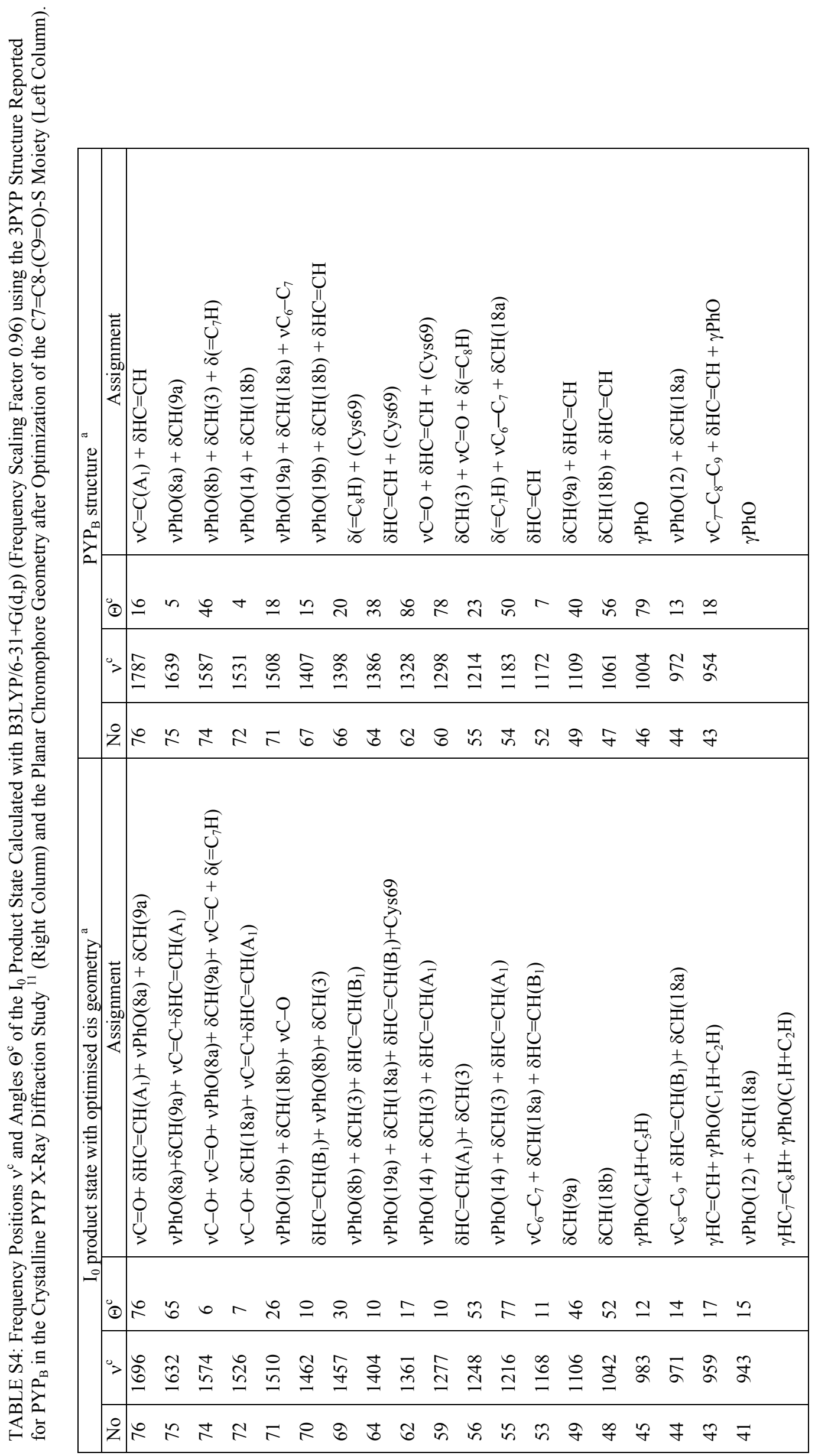




\section{References}

(1) Kim, M.; Mathies, R. A.; Hoff, W. D.; Hellingwerf, K. J. Biochemistry 1995, 34, 12669-12672.

(2) Zhou, Y.; Ujj, L.; Meyer, T. E.; Cusanovich, M. A.; Atkinson, G. H. J. Phys. Chem. A 2001, 105, 5719-5726.

(3) Unno, M.; Kumauchi, M.; Sasaki, J.; Tokunaga, F.; Yamauchi, S. J. Phys. Chem. B 2003, 107, 2837-2845.

(4) Unno, M.; Kumauchi, M.; Hamada, N.; Tokunaga, F.; Yamauchi, S. J. Biol. Chem. 2004, 279, 23855-23858.

(5) Imamoto, Y.; Mihara, K.; Hisatomi, O.; Kataoka, M.; Tokunaga, F.; Bojkova, N.; Yoshihara, K. J. Biol. Chem. 1997, 272, 12905-12908.

(6) Brudler, R.; Rammelsberg, R.; Woo, T. T.; Getzoff, E. D.; Gerwert, K. Nat. Struct. Biol. 2001, 8, 265-270.

(7) Imamoto, Y.; Shirahige, Y.; Tokunaga, F.; Kinoshita, T.; Yoshihara, K.; Kataoka, M. Biochemistry 2001, 40, 8997-9004.

(8) van Thor, J. J.; Pierik, A. J.; Nugteren-Roodzant, I.; Xie, A. H.; Hellingwerf, K. J. Biochemistry 1998, 37, 16915-16921.

(9) Unno, M.; Kumauchi, M.; Sasaki, J.; Tokunaga, F.; Yamauchi, S. Biochemistry 2002, 41, 5668-5674.

(10) Groot, M. L.; van Wilderen, L. J. G. W.; Larsen, D. S.; van der Horst, M. A.; van Stokkum, I. H. M.; Hellingwerf, K. J.; van Grondelle, R. Biochemistry 2003, 42, 10054-10059.

(11) Genick, U. K.; Soltis, S. M.; Kuhn, P.; Canestrelli, I. L.; Getzoff, E. D. Nature 1998, 392, 206-209.

(12) Getzoff, E. D.; Gutwin, K. N.; Genick, U. K. Nat. Struct. Biol. 2003, 10, 663-668.

(13) Düx, P.; Rubinstenn, G.; Vuister, G. W.; Boelens, R.; Mulder, F. A. A.; Hard, K.; Hoff, W. D.; Kroon, A. R.; Crielaard, W.; Hellingwerf, K. J.; Kaptein, R. Biochemistry 1998, 37, 1268912699. 